\title{
Familial aggregation and heritability of sarcoidosis: a Swedish nested case-control study
}

\author{
Marios Rossides (10) ${ }^{1}$, Johan Grunewald ${ }^{2,3,4}$, Anders Eklund ${ }^{2,3,4}$, \\ Susanna Kullberg ${ }^{2,3,4}$, Daniela Di Giuseppe ${ }^{1}$, Johan Askling ${ }^{1,5}$ and \\ Elizabeth V. Arkema (i) 1
}

Affiliations: ${ }^{1}$ Clinical Epidemiology Division, Dept of Medicine Solna, Karolinska Institutet, Stockholm, Sweden. ${ }^{2}$ Respiratory Medicine Division, Dept of Medicine Solna, Karolinska Institutet, Stockholm, Sweden. ${ }^{3}$ Center for Molecular Medicine, Karolinska Institutet, Stockholm, Sweden. ${ }^{4}$ Dept of Respiratory Medicine, Karolinska University Hospital, Stockholm, Sweden. ${ }^{5}$ Dept of Rheumatology, Karolinska University Hospital, Stockholm, Sweden.

Correspondence: Marios Rossides, Karolinska Institutet, Dept of Medicine Solna, Clinical Epidemiology Division, T2, 17176 Stockholm, Sweden. E-mail: marios.rossidesaki.se

@ERSpublications

Having relatives with sarcoidosis is a strong risk factor for the disease; $39 \%$ of the susceptibility is due to genetics http://ow.ly/67QL30kvKvu

Cite this article as: Rossides $\mathrm{M}$, Grunewald J, Eklund A, et al. Familial aggregation and heritability of sarcoidosis: a Swedish nested case-control study. Eur Respir J 2018; 52: 1800385 [https://doi.org/ $10.1183 / 13993003.00385-2018]$.

ABSTRACT Sarcoidosis is believed to be caused by both genetic and environmental risk factors, but the proportion of the susceptibility to sarcoidosis that is mediated by genetics remains unknown. We aimed to estimate the familial aggregation and heritability of sarcoidosis using a case-control-family study design and population-based Swedish registers.

We identified 23880 individuals with visits for sarcoidosis in the Swedish National Patient Register using International Classification of Diseases codes (1964-2013). Information on Löfgren's syndrome was available for a subset diagnosed at Karolinska University Hospital (Stockholm, Sweden). General population controls were matched to cases (10:1). Relatives of cases and controls were identified from the Swedish Multi-Generation Register and ascertained for sarcoidosis in the National Patient Register. We estimated familial relative risks for sarcoidosis using conditional logistic regression and heritability using biometric models.

Having at least one first-degree relative with sarcoidosis was associated with a 3.7 -fold increase in the risk of sarcoidosis (95\% CI 3.4-4.1). The relative risk increased in those with two or more relatives (relative risk 4.7) and in Löfgren's syndrome (relative risk 4.1). The heritability was 39\% (95\% CI 12-65\%).

This large investigation showed that having a relative with sarcoidosis is a very strong risk factor for the disease. Genetic variation is an important, albeit partial, contributing factor to the risk for sarcoidosis. 


\section{Introduction}

Sarcoidosis is a systemic granulomatous disease affecting mostly the pulmonary and lymphatic systems. Granulomatous formations suggest that an exogenous agent causes an immunological response in a genetically predisposed individual [1]. In fact, over the years, several loci in the human genome have been implicated in the pathophysiology of the disease [2-8]. However, what proportion of the susceptibility to sarcoidosis is mediated by genetics remains unknown.

Despite several anecdotal reports of familial clustering [9-14], only a few studies reported familial relative risks for sarcoidosis (table 1). The largest of those studies, the Case Control Etiologic Study of Sarcoidosis (ACCESS) showed that having first-degree relatives with the disease increased the risk of sarcoidosis by almost four-fold overall, and 17-fold for White Americans in particular [15]. In another investigation, the familial relative risk was estimated to be 2.5 in an African American population [16], while it ranged from 36 to 73 in a study from the UK [17]. All previous studies used questionnaires to identify relatives and ascertain their sarcoidosis status, which may have introduced bias. Some earlier investigations did not use active control groups or used unconventional statistical methods.

Familial aggregation estimates for different sarcoidosis phenotypes, such as Löfgren's versus non-Löfgren's disease, remain unknown. Löfgren's syndrome is a distinct sarcoidosis phenotype that presents with fever, bilateral hilar lymphadenopathy, arthritis and erythema nodosum [1]. It is characterised by acute-onset, distinct pathophysiology $[7,18-20]$ and more favourable prognosis compared to other disease presentations $[1,18]$.

Familial clustering of disease is suggestive of shared genetic or environmental factors among family members. Heritability is a population statistic used to summarise the proportion of variation in a phenotypic trait predicted by genotypic variation in a population. Heritability of sarcoidosis was estimated to be $60-70 \%$ in two very small studies (table 1) $[11,21]$, indicating that genetics play a major role in the development of the disease. However, much lower heritability estimates were reported from genome-wide association studies, in which identified genetic loci accounted for $<5 \%$ of the susceptibility to sarcoidosis $[6,7]$.

Investigating the familial aggregation and heritability of sarcoidosis is valuable for better understanding the aetiology of sarcoidosis and guiding future epidemiological and molecular research. It is clinically relevant, as familial relative risks could be used for patient counselling and aid differential diagnosis. The specific objectives of our study were to estimate 1) familial aggregation estimates, overall and stratified by age at diagnosis, sex, kinship, number of affected relatives and sarcoidosis phenotype and 2) the heritability of sarcoidosis, using population-based Swedish registry data.

\section{Methods \\ Study design and data sources}

We conducted a case-control-family study nested in Swedish population-based registers. In Sweden, residents are assigned a personal identification number that can be used to link their records in registers. Access to healthcare is universal and largely provided by tax-funded hospitals. Interactions with the healthcare system are captured by the National Patient Register (NPR). International Classification of Diseases (ICD)-coded discharge diagnoses for hospitalisations have been recorded since 1964 (nationwide coverage since 1987) and for outpatient non-primary care visits since 2001. Missing visits in the inpatient component are negligible, but the coverage of the outpatient component was less complete, with $\sim 10 \%$ of the visits not registered [22]. The NPR is expected to have good coverage for sarcoidosis, as most patients with the disease receive care in publicly funded outpatient clinics. The Multi-Generation Register (MGR) links registered residents from 1961 onwards to their biological or adoptive parents [23]. It is an excellent resource to identify relatives of individuals born in Sweden.

\section{Proband cases and controls}

Proband cases (individuals with sarcoidosis whose relatives were ascertained) were identified from the NPR using ICD codes (ICD-8/9 135, ICD-10 D86 including all subcategories). They were included if they were hospitalised at least once or had at least two outpatient visits for sarcoidosis from 1964 to 2013. The date of hospitalisation or second outpatient visit was the index date. For a subset of cases $(\mathrm{n}=983)$ who were diagnosed by pulmonologists at Karolinska University Hospital (Stockholm, Sweden), we could obtain information on sarcoidosis phenotype (Löfgren's versus non-Löfgren's disease).

Controls without sarcoidosis were sampled from the general population (Total Population Register) and were individually matched 10:1 to cases on birth year, sex, county of residence and date of inclusion. To reduce the likelihood of sarcoidosis misclassification, we excluded individuals aged $<18$ years at inclusion and those diagnosed with a haematological or lung malignancy within 6 months of the index date in the Swedish Cancer Register (ICD-7 162, 163, 200-205). As coverage of the MGR is incomplete for 
TABLE 1 Summary of previous studies on familial aggregation and heritability of sarcoidosis. Only familial aggregation studies with a control group were considered for this table

\begin{tabular}{|c|c|c|c|c|c|c|c|c|c|}
\hline \multirow[t]{2}{*}{$\begin{array}{l}\text { First author, year of } \\
\text { publication [ref.] }\end{array}$} & \multirow[t]{2}{*}{ Country } & \multicolumn{2}{|c|}{ Probands $\mathrm{n}$} & \multirow[t]{2}{*}{ Relatives n } & \multicolumn{2}{|c|}{$\begin{array}{c}\text { Mean age at inclusion } \\
\text { years }\end{array}$} & \multicolumn{2}{|c|}{ Sarcoidosis ascertainment } & \multirow[t]{2}{*}{ Estimates of familial aggregation/heritability } \\
\hline & & Cases & Controls & & Cases & Relatives & Probands & Relatives & \\
\hline Headings, 1976 [11] & USA & 80 & $\begin{array}{l}\text { Prevalence } \\
\text { estimate }\end{array}$ & $\begin{array}{l}523 \text { parents } \\
\text { and full } \\
\text { siblings }\end{array}$ & 34 & $\begin{array}{l}\text { Not } \\
\text { reported }\end{array}$ & Biopsy proven & $\begin{array}{l}\text { Reported by } \\
\text { probands }\end{array}$ & $\begin{array}{c}7.2 \% \text { of proband cases with } \geqslant 1 \text { FDR with } \\
\text { sarcoidosis } \\
\text { Heritability: } 60-70 \%\end{array}$ \\
\hline McGrath, 2000 [17] & UK & 406 & $\begin{array}{l}\text { Prevalence } \\
\text { estimate }\end{array}$ & Not reported & 40 & $\begin{array}{l}\text { Not } \\
\text { reported }\end{array}$ & $\begin{array}{l}\text { Biopsy and } \\
\text { non-biopsy } \\
\text { proven }\end{array}$ & $\begin{array}{l}\text { Reported by } \\
\text { proband, } \\
\text { confirmed by } \\
\text { family doctor }\end{array}$ & $\begin{array}{c}5.9 \% \text { of proband cases with } \geqslant 1 \text { family member } \\
\text { with sarcoidosis } \\
\text { Relative risk in siblings: } 36-73\end{array}$ \\
\hline RYBICKI, 2001 [15] & USA & 706 & 706 & $\begin{array}{l}10862 \text { FDRs } \\
17047 \text { SDRs }\end{array}$ & $\begin{array}{c}42 \\
\text { (median) }\end{array}$ & $\begin{array}{l}\text { Not } \\
\text { reported }\end{array}$ & Biopsy proven & $\begin{array}{l}\text { Reported by } \\
\text { proband }\end{array}$ & $\begin{array}{l}\text { Odds ratio in FDRs: } 3.8(1.9-7.6) \\
\text { Odds ratio in SDRs: } 5.2(1.5-18.2)\end{array}$ \\
\hline RYвıскі, 2001 [16] & USA & 179 & $\begin{array}{l}\text { Prevalence } \\
\text { estimate and } \\
\text { simulation }\end{array}$ & $\begin{array}{l}488 \text { parents } \\
\text { and full } \\
\text { siblings }\end{array}$ & 43 & $\begin{array}{l}\quad 66 \text { in } \\
\text { parents, } 45 \\
\text { in siblings }\end{array}$ & $\begin{array}{l}\text { Biopsy and } \\
\text { non-biopsy } \\
\text { proven }\end{array}$ & $\begin{array}{l}\text { Reported by } \\
\text { relative }\end{array}$ & Relative risk in FDRs: 2.5 (1.6-3.7) \\
\hline SVERRILD, 2008 [21] & $\begin{array}{l}\text { Denmark } \\
\text { and Finland }\end{array}$ & 210 & NA & $\begin{array}{l}210 \text { twin } \\
\text { pairs (50 MZ, } \\
160 \mathrm{DZ} \text { ) }\end{array}$ & $\begin{array}{l}\text { Not } \\
\text { reported }\end{array}$ & NA & Register-based & NA & $\begin{array}{c}\text { Concordance rates: } 0.148 \text { in MZ twins, } 0.012 \text { in } \\
\text { DZ twins } \\
\text { Heritability: } 66 \%(45-80 \%)\end{array}$ \\
\hline
\end{tabular}


foreign-born individuals, we excluded cases and controls born outside Sweden to ensure consistent identifiability of their relatives and increase the ethnic homogeneity of our study population.

\section{Identification of relatives and ascertainment of sarcoidosis}

First- and second-degree relatives of proband cases and controls were identified from the MGR. In our study, parents, full siblings and offspring of probands composed first-degree kinships (50\% genetic similarity), and half siblings composed second-degree kinships (25\% genetic similarity). Full siblings were defined as those sharing the same biological parents, whereas half siblings shared only one biological parent. As disease aggregation is a function of family size, the similarity of familial structures of proband cases and controls was confirmed to ensure fair comparisons. The same definition of sarcoidosis used to identify proband cases was used to ascertain sarcoidosis in relatives of cases and controls. Ethical approval for the study was obtained from the regional ethics review board in Stockholm (DNR 2014/230-31).

\section{Statistical analysis}

To measure the degree of familial aggregation of sarcoidosis, we used conditional logistic regression models estimating odds ratios, which we interpreted as familial relative risks. Unless otherwise stated, the familial relative risk in our study indicates the relative risk of sarcoidosis associated with having relatives with the disease irrespective of the timing of diagnosis of proband and relative. Two different modelling strategies were employed. In the first, each proband-relative relationship contributed a separate observation in our dataset and familial relative risks were reported for different kinships. To account for the lack of statistical independence due to family clustering, robust sandwich variance estimators were used to construct $95 \%$ confidence intervals. In the second modelling approach, we compared proband cases and controls who had at least one (or at least two) first-degree relatives diagnosed with sarcoidosis at any time point during the ascertainment period (1964-2013).

We have previously shown that the average age at disease diagnosis in Sweden is 50 years, but there is great variation by sex, with incidence peaking 10 years later in females compared to males [24]. To examine if such variations could be attributed to familial aggregation (and potentially genetics), we stratified our models by age at diagnosis and sex of the proband and relative. In addition, the model was stratified by disease phenotype (Löfgren's versus non-Löfgren's disease) for cases captured in the Karolinska clinical cohort.

We estimated the heritability of sarcoidosis using a threshold-liability model [25] incorporating a time aspect [26]. To estimate the proportion of variance attributable to additive genetic and shared environmental factors, we used probit variance component analysis. Methods of weight and prevalence estimation are described extensively elsewhere [26-29]. We included full and half siblings born within 10 years of the proband case or control (i.e. assumed to be reared together), and we right-censored individuals at age 80 years to account for the lifetime risk for sarcoidosis.

We performed several sensitivity analyses described in detail in the online supplementary material. Data management and analyses were performed using SAS software (version 9.4; SAS Institute, Cary, NC, USA) and $\mathrm{R}$ version 3.4.2 (R Foundation for Statistical Computing, Vienna, Austria).

TABLE 2 Family structure of proband cases and controls with at least one first- or second-degree relative identified from the Swedish Multi-Generation Register

\begin{tabular}{|c|c|c|c|c|}
\hline & \multicolumn{2}{|c|}{ Cases $^{\#}$} & \multicolumn{2}{|c|}{ Controls $\#$} \\
\hline & Relatives & Relatives per case & Relatives & Relatives per control \\
\hline \multicolumn{5}{|c|}{ First-degree relatives } \\
\hline All relatives & 86136 & $4.2(2.2)$ & 713708 & $4.3(2.2)$ \\
\hline Parents & 28835 & $1.4(0.9)$ & 245054 & $1.5(0.8)$ \\
\hline Full siblings & 24104 & $1.2(1.4)$ & 203989 & $1.2(1.4)$ \\
\hline Offspring & 33197 & $1.6(1.4)$ & 264665 & $1.6(1.4)$ \\
\hline \multicolumn{5}{|c|}{ Second-degree relatives } \\
\hline Half siblings & 7511 & $2.1(1.6)$ & 15202 & $2.1(1.5)$ \\
\hline
\end{tabular}

Data are presented as $n$ or mean \pm SD. ${ }^{\#}$ : probands with $\geqslant 1$ first-degree relative $n=20322$ cases, $n=164628$ controls; probands with $\geqslant 1$ second-degree relative $n=3558$ cases, $n=7263$ controls. 


\section{Results}

Our study included 23880 proband cases with prevalent sarcoidosis and 171891 non-sarcoidosis controls from the general population with at least one first- or second-degree relative. The mean $\pm S D$ age of probands at inclusion was $50 \pm 16.0$ years and $47 \%$ were female. The family structures of cases and controls were very similar with an average of four first-degree relatives identified per case or control (table 2). In addition, the age and sex distributions of relatives of proband cases and controls were similar (online supplementary table E1).

\section{Familial relative risk for sarcoidosis}

Table 3 provides a summary of the relative risks for sarcoidosis associated with having relatives of different degree diagnosed with sarcoidosis. $\sim 4 \%$ of proband cases had at least one first-degree relative diagnosed with the disease, whereas only $1 \%$ of proband controls had at least one first-degree relative diagnosed with sarcoidosis. The familial relative risk associated with having at least one first-degree relative with the disease was 3.73 (95\% CI 3.43-4.06). The familial relative risk for sarcoidosis increased to 4.69 (95\% CI 2.93-7.51) when at least two first-degree relatives were diagnosed with sarcoidosis in a family and was attenuated to 1.50 (95\% CI 0.98-2.30) when a second-degree relative (a half sibling) was diagnosed with the disease. No great differences in the familial relative risk among first-degree kinships were observed (table 3).

Stratifications of the familial relative risk associated with having at least one first-degree relative with the disease by age of the proband, sex of proband and relative and Löfgren's syndrome are shown in figure 1. The relative risk for sarcoidosis was higher for probands aged 18-49 years at the time of inclusion in the study compared to those aged $\geqslant 50$ years $(3.99,95 \%$ CI $3.55-4.48$ versus $3.48,95 \%$ CI $3.08-3.92$, respectively). The relative risk was higher for male proband to female relative relationships (4.10, 95\% CI 3.49-4.82) compared to other sex combinations, for which the relative risk was centred on 3.5. In addition, there was an indication of increased familial relative risk for individuals in the clinical cohort whose disease manifested as Löfgren's compared to non-Löfgren's disease manifestations (4.14. 95\% CI 2.21-7.75 versus 3.32, 95\% CI 1.98-5.56, respectively). Stratified analyses by age and sex among different kinships are provided in online supplementary tables E2 and E3, respectively.

Restricting our analyses to probands with a history of disease $\geqslant 1$ year before inclusion yielded similar results (online supplementary table E4). In addition, the familial relative risk from the main analyses proved robust in a probabilistic bias analysis where our register-based definition of sarcoidosis was subjected to extreme misclassification and when we used a stricter definition for sarcoidosis, requiring at least two visits in the NPR listing sarcoidosis (online supplementary table E5).

\section{Heritability of sarcoidosis}

The heritability of the disease was estimated to be 39\% (95\% CI 12-65\%) from an additive genetic and nonshared environmental variance model (figure 2). No modification of heritability was observed by sex of the proband. No variance attributable to shared environment between siblings could be identified in the data. Estimations of the ceiling heritability using Falconer's formulae provided similar results (online supplementary table E6).

TABLE 3 Relative risk of sarcoidosis associated with having relatives with the disease

Cases exposed

Controls exposed

Relative risk $(95 \% \mathrm{Cl})$

First-degree relatives
$\geqslant 1$ relative $^{\#}$
$\geqslant 2$ relatives
Parents
Full siblings"
Offspring
Second-degree relatives
Half siblings

$831 / 20332(4.1)$
$28 / 20332(0.1)$
$271 / 28835(0.9)$
$330 / 24104(1.4)$
$262 / 33197(0.8)$

$44 / 7511(0.6)$

$1907 / 164628(1.2)$
$49 / 164628(<0.1)$
$638 / 245054(0.3)$
$696 / 203989(0.3)$
$623 / 264665(0.2)$

49/15202 (0.3)
$3.73(3.43-4.06)$

$4.69(2.93-7.51)$

$3.68(3.23-4.19)$

$4.08(3.45-4.83)$

$3.23(2.78-3.76)$

$1.50(0.98-2.30)$

Data are presented as $\mathrm{n} / \mathrm{N}(\%)$, unless otherwise stated. The confidence intervals were adjusted for autocorrelation arising from family clustering using robust estimates of the variance. ${ }^{\text {: }}$ : for these analyses, an indicator for having more than one or two first-degree relatives with sarcoidosis was created for each case and control; $\eta_{\text {: }}$ for these analyses, each proband-relative relationship contributed a unique observation in the dataset. 


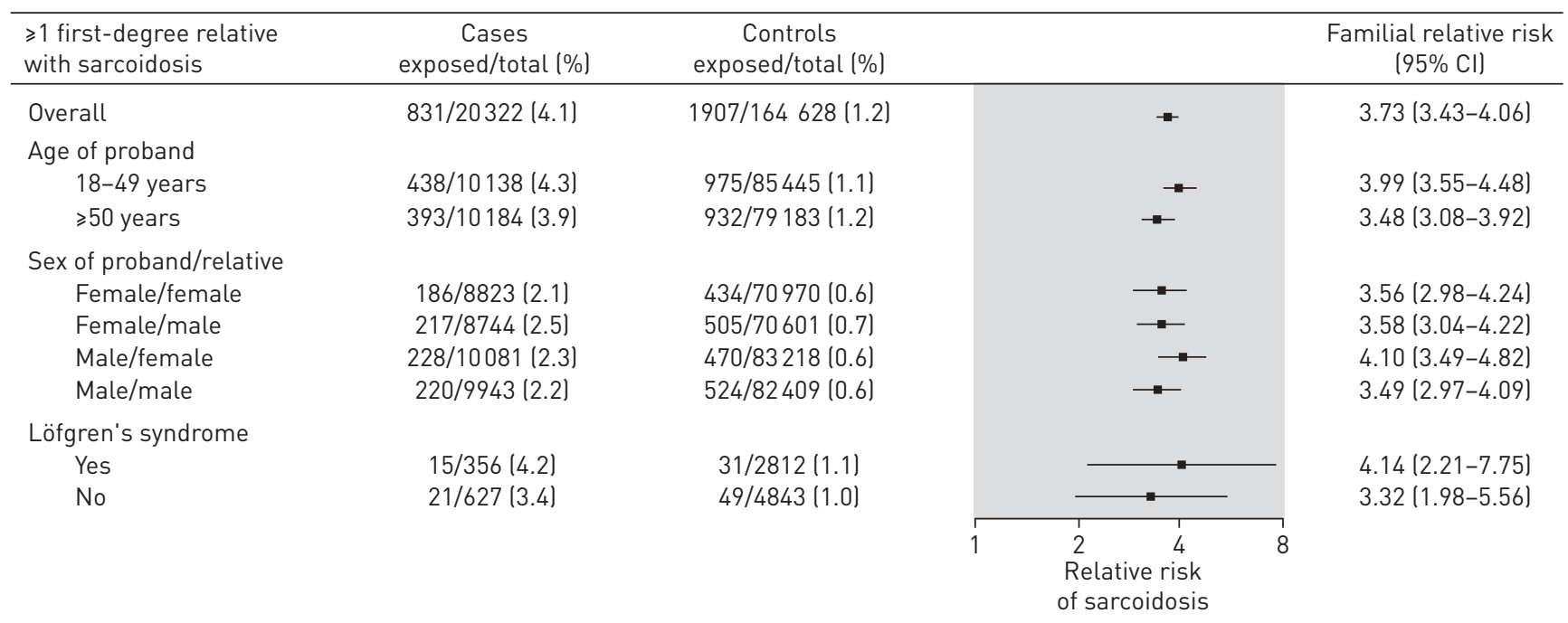

FIGURE 1 Relative risk of sarcoidosis associated with having at least one first-degree relative with sarcoidosis, stratified by age of the proband at inclusion, sex of proband and relative and Löfgren's syndrome.

FIGURE 2 Additive genetic (heritability) and nonshared environmental effects contributing to the susceptibility for sarcoidosis, overall and stratified by the sex of the proband.
Nonshared environmental effects

Additive genetic effects

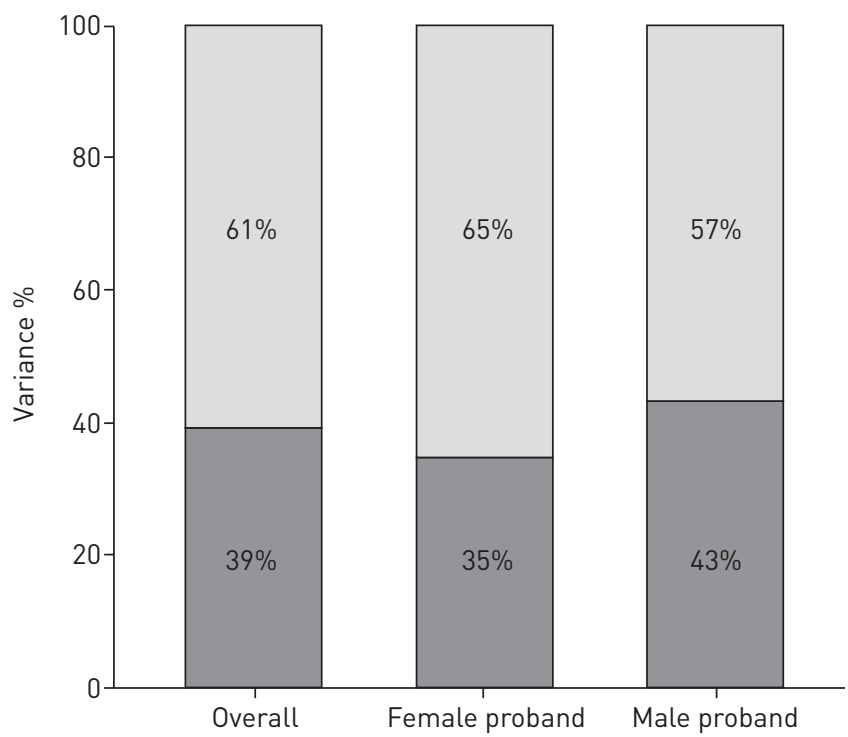

\section{Discussion}

To our knowledge, this case-control-family study represents the largest investigation to date aiming to estimate the familial aggregation of sarcoidosis. Using population-based Swedish registers with coverage spanning three generations, we show that familial exposure is likely the strongest risk factor for sarcoidosis described to date, associated with an almost four-fold increased risk of developing the disease. The variation in familial relative risk by number of affected relatives, type of kinship and age at sarcoidosis diagnosis further provides evidence that genetics influence, at least partly, the development of sarcoidosis. Using biometric model analysis, we show that the heritability is $39 \%$.

In previous studies, reported familial relative risks for first-degree relatives range from 2.5 to 73.0 [15-17]. The absence of a control group and the small sample size of most previous investigations [16, 17] make comparison to our study difficult. However, our findings are comparable to those reported by the ACCESS study comprising 701 White and Black American cases and controls [15]. The overall familial relative risk for first-degree relatives is very similar to ours (odds ratio 3.8), but they reported higher risks for siblings and second-degree relatives (odds ratios 5.8 and 5.2, respectively). When restricting to White American probands in the ACCESS study, the odds ratio was 16.6 [15]. It is difficult to disentangle the reasons 
behind the observed dissimilarities. There are evident differences in the methodology used for disease ascertainment and, importantly, the ethnic composition of the ACCESS participants and our study population. Differences in the analytical approach and the limited power of some analyses in the ACCESS study could be alternative explanations for some of the discrepancies.

Contrary to the ACCESS study [15], but in line with another study [16], we observed a higher familial relative risk for those diagnosed before the age of 50 years compared to aged $\geqslant 50$ years and for male-female proband-relative relationships compared to other relationships. Although the observed weak effect measure modification by age might be interpreted as an indication of the involvement of genetics in disease aetiology, we cannot exclude the possibility that this resulted from a slight overrepresentation of male probands in the younger age group, for whom sarcoidosis prevalence is higher, as we have previously shown [24]. However, further stratification by sex of the proband did not eliminate the effect of age (data not shown). Conversely, the observed higher relative risk for male-female proband-relative relationships did not persist when we stratified by kinship, suggesting that the observed modification by sex was merely a feature of our data.

Despite small numbers, analyses using information on sarcoidosis phenotype from our clinical cohort at Karolinska University Hospital indicated stronger familial associations for disease manifesting as Löfgren's compared to non-Löfgren's disease. This is in line with previous investigations describing Löfgren-like disease being somewhat more prevalent in familial than nonfamilial disease $[13,30]$. While this finding needs more exploration and replication by other studies, it may be suggestive of a stronger genetic association in Löfgren's compared to non-Löfgren's disease [7], providing also a reasonable, albeit partial, explanation for the differences between the two manifestations of sarcoidosis in terms of phenotype and prognosis [18-20].

$39 \%$ of the liability to sarcoidosis was attributed to additive genetic factors in our population, while the contribution of shared environmental factors and the effect of sex were negligible. The prominent role of environmental factors in the aetiology of sarcoidosis is not surprising. Factors ranging from infectious agents [31] and mould [32, 33] to nanoparticles [34] have been implicated in sarcoidosis. The specific roles of these factors and their potential to explain the environmental component of sarcoidosis susceptibility remain to be fully elucidated.

The heritability of $39 \%$ we found in our population contrasts with the notion that genetics might be more influential than environmental factors for the liability to sarcoidosis, as suggested by earlier reports from the United States [11] and Finland/Denmark [21]. Despite differences in definition of sarcoidosis and the ethnic composition of our population, we believe that low power is likely the primary reason for the inflated heritability estimates in previous studies. Additionally, under certain circumstances, Falconer's method and the twin-study design used in those studies are prone to overestimation of heritability [35]. Nevertheless, we should not disregard the fact that even among more similar populations and environments in Sweden, Denmark and Finland, particularities of the microenvironment and local genetic variation (e.g. founder effects) may alter to some extent the balance between the genetic and environmental components of sarcoidosis susceptibility.

The heritability estimates reported in our study are different to estimates originating from genome-wide association studies $[6,7]$. A number of common sarcoidosis single nucleotide polymorphisms accounted only for $5 \%$ overall [6], and $4 \%$ and $2 \%$ of the phenotypic variability of Löfgren's and non-Löfgren's disease, respectively [7]. These low numbers highlight the fact that genome-wide association studies cannot yet capture all genetic variance in the population ("missing heritability"), probably due to small sample sizes or the inability to identify certain genetic effects $[36,37]$, such as rare gene variants that have been identified by other methods [38].

A limitation of our study originates from the change in the availability of data in the NPR to define sarcoidosis over time. Our capacity to ascertain sarcoidosis increased considerably since 2001 with the capture of outpatient visits by the NPR. Before then, only hospitalisation data were available, hence cases and relatives identified in the earlier period likely represent a smaller group of cases with more severe disease. It is possible that a few controls had asymptomatic disease when they were sampled or developed sarcoidosis later. This may have resulted in a slight underestimation of familial relative risks and heritability. In addition, in the absence of histological or clinical confirmation of cases, using a register-based definition might have led to some misclassification. However, familial relative risks remained robust when our sarcoidosis definition was subjected to extreme misclassification using probabilistic bias analysis methods and when a stricter definition was used.

Our heritability estimations were based on a set of assumptions that should be considered when interpreting the results. We assumed that the liability to sarcoidosis was normally distributed, the prevalence of sarcoidosis was correctly specified, that there was no assortative mating, genetic effects were additive (no epistasis or dominance among loci), and that there were no gene-environment interactions. 
While such assumptions may not be perceived extreme, they are indeed difficult to test. Last, we cannot assume that our familial relative risk and heritability estimates are readily generalisable to all populations, as they reflect the genetic composition and environmental exposures in the Swedish context.

Our study has several strengths. By using population-based registers, we estimated valid and precise familial aggregation and heritability estimates. Our study was well powered to obtain informative stratified estimates of familial relative risks. In addition, having access to a well-described clinical cohort allowed us to complement our findings with an estimate of the familial aggregation of Löfgren's and non-Löfgren's sarcoidosis. Future research efforts should focus on the familial aggregation of other disease phenotypes, disease complications and disease prognosis.

In summary, familial exposure to sarcoidosis is a very strong risk factor for the disease. Having at least one first-degree relative with sarcoidosis is associated with an almost four-fold increased risk for the disease. There was a trend towards increased familial relative risks with higher number of affected relatives, if disease is diagnosed before the age of 50 years, and for Löfgren's syndrome. The heritability of the disease was 39\%, suggesting a stronger implication of environmental factors in the development of sarcoidosis than what was previously perceived. Future research efforts should focus on identifying environmental agents implicated in the aetiology of sarcoidosis and unidentified genetic factors that could account for the missing heritability of sarcoidosis.

Acknowledgements: The authors would like to thank patients and healthcare personnel contributing data to the clinical cohort at Karolinska University Hospital.

Author contributions: Conception and design of the study: M. Rossides, E.V. Arkema; data analysis: M. Rossides; interpretation of data: all authors; drafting of first manuscript: M. Rossides; critical revision for important intellectual content: all authors; final approval of the version to be submitted: all authors; agreement to be accountable for all aspects of this study: all authors.

Conflict of interest: E.V. Arkema reports grants from Swedish Heart-Lung Foundation and Swedish Society of Medicine, during the conduct of the study.

Support statement: This study received funding from the Swedish Heart-Lung Foundation. The register linkage used in this study was also funded by the Swedish Society of Medicine. The funders had no role in study design, data collection and analysis, decision to publish, or preparation of the manuscript. Research on sarcoidosis at Karolinska Institutet is supported by the Swedish Research Council, the Swedish Foundation for Strategic Research, the Strategic Research Area in Epidemiology (SfoEpi), a regional agreement on medical training and clinical research (ALF) between the Stockholm County Council and Karolinska Institutet, King Oscar's II Jubilee Foundation, the King Gustaf V's and Queen Victoria's Freemasons' Foundation and Karolinska Institutet's Research Foundation. Funding information for this article has been deposited with the Crossref Funder Registry.

\section{References}

1 Statement on sarcoidosis. Joint Statement of the American Thoracic Society (ATS), the European Respiratory Society (ERS) and the World Association of Sarcoidosis and Other Granulomatous Disorders (WASOG) adopted by the ATS Board of Directors and by the ERS Executive Committee, February 1999. Am J Respir Crit Care Med 1999; 160: 736-755.

2 Schürmann M, Reichel P, Müller-Myhsok B, et al. Results from a genome-wide search for predisposing genes in sarcoidosis. Am J Respir Crit Care Med 2001; 164: 840-846.

3 Iannuzzi MC, Iyengar SK, Gray-McGuire C, et al. Genome-wide search for sarcoidosis susceptibility genes in African Americans. Genes Immun 2005; 6: 509-518.

4 Franke A, Fischer A, Nothnagel M, et al. Genome-wide association analysis in sarcoidosis and Crohn's disease unravels a common susceptibility locus on 10p12.2. Gastroenterology 2008; 135: 1207-1215.

5 Adrianto I, Lin CP, Hale JJ, et al. Genome-wide association study of African and European Americans implicates multiple shared and ethnic specific loci in sarcoidosis susceptibility. PLoS One 2012; 7: e43907.

6 Fischer A, Ellinghaus D, Nutsua M, et al. Identification of immune-relevant factors conferring sarcoidosis genetic risk. Am J Respir Crit Care Med 2015; 192: 727-736.

7 Rivera NV, Ronninger M, Shchetynsky K, et al. High-density genetic mapping identifies new susceptibility variants in sarcoidosis phenotypes and shows genomic-driven phenotypic differences. Am J Respir Crit Care Med 2016; 193: 1008-1022.

8 Wolin A, Lahtela EL, Anttila V, et al. SNP variants in major histocompatibility complex are associated with sarcoidosis susceptibility - a joint analysis in four European populations. Front Immunol 2017; 8: 422.

$9 \quad$ Wiman LG. Familial occurrence of sarcoidosis. Scand J Respir Dis Suppl 1972; 80: 115-119.

10 Familial associations in sarcoidosis. A report to the Research Committee of the British Thoracic and Tuberculosis Association. Tubercle 1973; 54: 87-98.

11 Headings VE, Weston D, Young RC Jr, et al. Familial sarcoidosis with multiple occurrences in eleven families: a possible mechanism of inheritance. Ann NY Acad Sci 1976; 278: 377-385.

12 Brennan NJ, Crean P, Long JP, et al. High prevalence of familial sarcoidosis in an Irish population. Thorax 1984; 39: 14-18.

13 Fité E, Alsina JM, Antó JM, et al. Sarcoidosis: family contact study. Respiration 1998; 65: 34-39.

14 Pietinalho A, Ohmichi M, Hirasawa M, et al. Familial sarcoidosis in Finland and Hokkaido, Japan - a comparative study. Respir Med 1999; 93: 408-412. 
15 Rybicki BA, Iannuzzi MC, Frederick MM, et al. Familial aggregation of sarcoidosis. A case-control etiologic study of sarcoidosis (ACCESS). Am J Respir Crit Care Med 2001; 164: 2085-2091.

16 Rybicki BA, Kirkey KL, Major M, et al. Familial risk ratio of sarcoidosis in African-American sibs and parents. Am J Epidemiol 2001; 153: 188-193.

17 McGrath DS, Daniil Z, Foley P, et al. Epidemiology of familial sarcoidosis in the UK. Thorax 2000; 55: 751-754.

18 Grunewald J, Eklund A. Löfgren's syndrome: human leukocyte antigen strongly influences the disease course. Am J Respir Crit Care Med 2009; 179: 307-312.

19 Grunewald J. HLA associations and Löfgren's syndrome. Expert Rev Clin Immunol 2012; 8: 55-62.

20 Sato H, Woodhead FA, Ahmad T, et al. Sarcoidosis HLA class II genotyping distinguishes differences of clinical phenotype across ethnic groups. Hum Mol Genet 2010; 19: 4100-4111.

21 Sverrild A, Backer V, Kyvik KO, et al. Heredity in sarcoidosis: a registry-based twin study. Thorax 2008; 63: 894-896.

22 Socialstyrelsen. Kvalitet och innehåll i patientregistret. Utskrivningar från slutenvården 1964-2007 och besök i specialiserad öppenvård (exklusive primärvårdsbesök) 1997-2007. [Quality and Contents of the Patient Register]. Stockholm, Socialstyrelsen (The National Board of Health and Welfare), 2009.

23 Statistics Sweden. Multi-Generation Register 2010. A Description of Contents and Quality. Örebro, Department of Population and Welfare Statistics, Statistics Sweden, 2011.

24 Arkema EV, Grunewald J, Kullberg S, et al. Sarcoidosis incidence and prevalence: a nationwide register-based assessment in Sweden. Eur Respir J 2016; 48: 1690-1699.

25 Falconer DS, Mackay TF. Introduction to Quantitative Genetics. 4th edn. Pearson, Harlow, 1996.

26 Cederkvist L, Holst KK, Andersen KK, et al. Incorporation of the time aspect into the liability-threshold model for case-control-family data. Stat Med 2017; 36: 1599-1618.

27 Scheike TH, Holst KK, Hjelmborg JB. Estimating heritability for cause specific mortality based on twin studies. Lifetime Data Anal 2014; 20: 210-233.

28 Holst KK, Scheike TH, Hjelmborg JB. The liability threshold model for censored twin data. Comput Stat Data An 2016; 93: 324-335.

29 Javaras KN, Laird NM, Hudson JI, et al. Estimating disease prevalence using relatives of case and control probands. Biometrics 2010; 66: 214-221.

30 Pacheco Y, Calender A, Israël-Biet D, et al. Familial vs. sporadic sarcoidosis: BTNL2 polymorphisms, clinical presentations, and outcomes in a French cohort. Orphanet J Rare Dis 2016; 11: 165.

31 Suzuki Y, Uchida K, Takemura T, et al. Propionibacterium acnes-derived insoluble immune complexes in sinus macrophages of lymph nodes affected by sarcoidosis. PLoS One 2018; 13: e0192408.

32 Newman LS, Rose CS, Bresnitz EA, et al. A case control etiologic study of sarcoidosis: environmental and occupational risk factors. Am J Respir Crit Care Med 2004; 170: 1324-1330.

33 Terčelj M, Salobir B, Harlander M, et al. Fungal exposure in homes of patients with sarcoidosis - an environmental exposure study. Environ Health 2011; 10: 8.

34 Huizar I, Malur A, Midgette YA, et al. Novel murine model of chronic granulomatous lung inflammation elicited by carbon nanotubes. Am J Respir Cell Mol Biol 2011; 45: 858-866.

35 Tenesa A, Haley CS. The heritability of human disease: estimation, uses and abuses. Nat Rev Genet 2013; 14: 139-149.

36 Manolio TA, Collins FS, Cox NJ, et al. Finding the missing heritability of complex diseases. Nature 2009; 461: 747-753.

37 Timpson NJ, Greenwood CMT, Soranzo N, et al. Genetic architecture: the shape of the genetic contribution to human traits and disease. Nat Rev Genet 2018; 19: 110-124.

38 Calender A, Rollat Farnier PA, Buisson A, et al. Whole exome sequencing in three families segregating a pediatric case of sarcoidosis. BMC Med Genomics 2018; 11: 23 